\title{
DEMOCRATIZAÇÃO DA INFORMAÇÃO E DO CONHECIMENTO POR MEIO DA ACESSIBILIDADE EM DOCUMENTOS DIGITAIS
}

\author{
DEMOCRATIZATION OF INFORMATION AND KNOWLEDGE BY MEANS \\ OF ACCESSIBILITY IN DIGITAL DOCUMENTS
}

\section{DEMOCRATIZACIÓN DE LA INFORMACIÓN Y DEL CONOCIMIENTO POR MEDIO DE LA ACCESIBILIDAD EN DOCUMENTOS DIGITALES}

Daniele dos Anjos Schmitz ${ }^{1}$, Ana Cláudia Oliveira Pavão

\begin{abstract}
RESUMO
A garantia ao acesso de pessoas com deficiência no ensino superior está prevista em lei. No entanto, a efetiva participação dos estudantes nos diferentes aspectos da vida acadêmica suscita preocupação, assim como a conclusão dos seus estudos. Então, para apoiar esse processo de inclusão, considerando a acessibilidade digital, o objetivo deste artigo é apresentar os resultados de uma pesquisa que mostra os dados de uma Instituição Federal de Ensino Superior (IFES) e o desenvolvimento de um manual de orientações para criação de documentos digitais acessíveis em editores de texto. Para a realização deste estudo, o referencial teórico traz informações relacionadas à acessibilidade e à democratização da informação e do conhecimento, bem como diretrizes e recomendações de acessibilidade. A abordagem metodológica envolveu pesquisa aplicada, com abordagem qualitativa, descritiva e do tipo estudo de caso do contexto da investigação. Os resultados apontaram que o manual é uma forma de contribuir com os servidores da universidade no processo de criação de documentos digitais acessíveis, atingindo-se assim os objetivos da pesquisa.
\end{abstract}

PALAVRAS-CHAVE: Democratização. Acessibilidade. Acesso à informação

\begin{abstract}
The guarantee for the access of persons with disabilities in higher education is provided by law. However, the effective participation of students in different aspects of academic life raises concern, as well as the conclusion of their studies. In order to support this inclusion process, considering the digital accessibility, the objective of this article is to present the results of a research that shows the data of a Federal Institution of Higher Education (IFES) and the development of a manual of guidelines for the creation of accessible digital documents in text editors. For this study, the theoretical framework brings information related to the accessibility and democratization of information and knowledge, as well as guidelines and recommendations for accessibility. The methodological approach involved applied research, with a qualitative, descriptive and case study type of the research context. The results pointed out that the manual is a way to contribute with the university's servers in the process of creating accessible digital documents, thus achieving the objectives of the research.
\end{abstract}

KEYWORDS: Democratization. Accessibility. Access to information

\section{RESUMEN}

La garantía del acceso de las personas con discapacidad en la enseñanza superior está prevista en la ley. Sin embargo, la efectiva participación de los estudiantes en los diferentes aspectos de la vida académica suscita

\footnotetext{
${ }^{1}$ Mestrado Profissional Tecnologias Educacionais em Rede - Universidade Federal de Santa Maria (UFSM) Santa Maria, RS - Brasil. Pedagoga da Universidade Federal do Pampa (UNIPAMPA) - Alegrete, RS - Brasil. Email: danieleschmitz@gmail.com

${ }^{2}$ Doutora em Informática na Educação - Universidade Federal do Rio Grande do Sul (UFRGS) - Porto Alegre, RS, Brasil. Professora Associada - Universidade Federal de Santa Maria (UFSM) - Santa Maria, RS - Brasil. Email: anaclaudiaoliveirapavao@gmail.com
}

(C) ETD- Educação Temática Digital Campinas, SP $\quad$ v.20 n.4 p.1117-1137 out./dez. 2018


preocupación, así como la conclusión de sus estudios. Por lo tanto, para apoyar este proceso de inclusión, considerando la accesibilidad digital, el objetivo de este artículo es presentar los resultados de una investigación que muestra los datos de una Institución Federal de Enseñanza Superior (IFES) y el desarrollo de un manual de orientaciones para la creación documentos digitales accesibles en los editores de texto. Para la realización de este estudio, el referencial teórico trae informaciones relacionadas a la accesibilidad ya la democratización de la información y del conocimiento, así como directrices y recomendaciones de accesibilidad. El enfoque metodológico involucró investigación aplicada, con abordaje cualitativo, descriptivo y del tipo estudio de caso del contexto de la investigación. Los resultados apuntaron que el manual es una forma de contribuir con los servidores de la universidad en el proceso de creación de documentos digitales accesibles, alcanzando así los objetivos de la investigación.

PALABRAS CLAVE: Democratización. Accesibilidad. Acceso a la información

\section{INTRODUÇÃO}

A acessibilidade no ensino superior está estabelecida em leis e decretos, tais como: Constituição Federal de 1988, que garante a Educação como direito de todos; Decreto no 7.611/2011, que prevê a estruturação de núcleo de acessibilidade nas instituições federais de ensino superior; Lei $n$ ㅇ 13.146/2015, a qual determina a obrigatoriedade de cumprimento das condições de acessibilidade em todos os níveis, etapas e modalidades de ensino; Lei no 13.409/2016, que dispõe sobre a reserva de vagas para pessoas com deficiência nos cursos técnicos de nível médio e superior das instituições federais de ensino, entre outras. Nesse sentido, Guerreiro aponta

para um aumento da legislação que trata das questões de acessibilidade para a pessoa com deficiência, como também para o crescimento dos estudos nos espaços educacionais, tanto do ensino básico como no superior. Aponta, também, que não basta a adequação desse espaço para que a inclusão escolar ocorra, é preciso que haja, igualmente, as adequações dos recursos pedagógicos e a capacitação do corpo docente e gestor (GUERREIRO, 2012, p. 227).

Do mesmo modo, a quantidade de matrículas de pessoas com deficiência na educação superior aumentou 518,66\% entre 2004 e 2014 (INEP, 2016). Esse índice assinala que as instituições de ensino necessitam estar preparadas para a realidade, proporcionando a todos o acesso à informação e ao conhecimento de forma democrática. Pereira et. al, afirmam que,

embora a matrícula e a presença do acadêmico estejam legalmente amparadas por lei, certas atitudes por parte da universidade podem favorecer a inclusão, assim como podem dificultar a participação do mesmo no contexto universitário. (PEREIRA, et. al., p. 159)

Pensando nessa necessidade de incluir o aluno, uma atitude que favorece a efetiva participação das pessoas com deficiência é a acessibilidade dos documentos digitais criados e disponibilizados em um ambiente educacional. Os documentos digitais são entendidos neste texto como documentos criados por servidores de uma universidade, em editores de texto, como materiais didáticos, apostilas, planos de aula, convites, divulgações, atestados, declarações, comprovantes, que podem ser acessados pelas pessoas, independente das suas características ou necessidades.

\footnotetext{
C ETD- Educação Temática Digital Campinas, SP

v. 20 n. 4

p.1117-1137

out./dez. 2018
} 
Essa é uma medida prevista na Lei № 12.527/2011, a qual presume, quanto ao acesso à informação e sua divulgação, entre outros requisitos, "adotar as medidas necessárias para garantir a acessibilidade de conteúdo para pessoas com deficiência" (BRASIL, 2011). Assim como o art. 63 da Lei no 13.146/2015, o qual dispõe que

\begin{abstract}
é obrigatória a acessibilidade nos sítios da internet mantidos por empresas com sede ou representação comercial no País ou por órgãos de governo, para uso da pessoa com deficiência, garantindo-lhe acesso às informações disponíveis, conforme as melhores práticas e diretrizes de acessibilidade adotadas internacionalmente (BRASIL, 2015).
\end{abstract}

Para que tal legislação seja efetivamente cumprida, há diretrizes que podem ser seguidas a fim de tornar conteúdos digitais mais acessíveis, como as Diretrizes de Acessibilidade para Conteúdo Web (WCAG) 2.0, elaboradas pelo World Wide Web Consortium (W3C), que definem a forma de tornar o conteúdo Web mais acessível não só às pessoas com deficiência, mas também aos usuários em geral. Existe ainda o Modelo de Acessibilidade do Governo Eletrônico (eMAG), que é uma versão especializada do WCAG, voltada para o governo brasileiro, cujo compromisso é o de ser o norteador no desenvolvimento e na adaptação de conteúdos digitais do governo federal, garantindo acessibilidade a todos. Os autores Amorim e Silva (2009) corroboram com essa ideia ao afirmarem que devemos

buscar soluções tecnológicas de alcance social que procurem diminuir diferenças e resgatar valores de cidadania, o que por sua vez tende a combater barreiras tecnológicas, educacionais, culturais, sociais e econômicas hoje presentes. (AMORIM; SILVA, 2009, p. 356)

Nesse sentido, é necessário pensar em criação de documentos em formatos acessíveis para garantir que um maior número de pessoas sejam incluídas e tenham direito à participação e, consequentemente, igualdade de oportunidades. Pensando nessas questões, foi realizado um levantamento de dados, no qual as pesquisadoras identificaram o grau de conhecimento dos servidores da universidade, com relação à criação de documentos digitais acessíveis. Como resultado, verificou-se que aproximadamente $67 \%$ dos respondentes não possuíam esse conhecimento. Além disso, a maioria deles informou que consideravam importante ter um manual direcionado à criação de documentos em editores de texto.

Somando-se a essa questão, observou-se que em 2016, a universidade possuía 1.079 estudantes regulares com alguma deficiência ou outras necessidades, correspondendo a $9,67 \%$ do total de estudantes matriculados, sendo que no período compreendido entre 2008 e 2016, percebeu-se um número significativo de estudantes com deficiência que evadiram da Instituição por abandono, cancelamento ou desligamento, totalizando mais de $10 \%$ do corpo discente, ou seja, 1.713 estudantes. Tais dados alertam sobre a necessidade de alternativas que garantam a eles condições de acessibilidade nos diferentes aspectos da vida acadêmica, dentre esses, a dos documentos digitais.

(C) ETD- Educação Temática Digital Campinas, SP $\quad$ v.20 n.4 p.1117-1137 $\quad$ out./dez. 2018 
Em vista dos dados apresentados, este estudo tem como objetivo desenvolver um manual com orientações para a criação de documentos digitais acessíveis nos editores de texto Microsoft Word 2010 e LibreOffice Writer para apoiar a realização das atividades dos servidores, docentes e técnico-administrativos em educação. Documentos acessíveis são entendidos, neste trabalho, como instrumentos de democratização da informação e do conhecimento.

A contribuição social desta pesquisa baseia-se em possibilitar o acesso aos documentos criados e disponibilizados, em formato digital, pelos servidores da universidade, ao maior número de pessoas possível, promovendo a inclusão digital, bem como diminuindo as desigualdades à medida que proporciona autonomia, independência e inserção social de pessoas com necessidades.

\section{ACESSIBILIDADE COMO FORMA DE DEMOCRATIZAÇÃO DA INFORMAÇÃO E DO CONHECIMENTO}

A acessibilidade beneficia todas as pessoas e não somente aquelas com deficiência (PD) ou necessidades educacionais especiais (NEE). Na busca pela definição da palavra, encontramos, no estudo de Petrie et al. (2015), a seguinte definição de acessibilidade Web:

Todas as pessoas, particularmente pessoas com deficiência e pessoas idosas, podem usar sites em uma variedade de contextos de uso, incluindo tecnologias tradicionais e assistivas; Para conseguir isso, os sites precisam ser projetados e desenvolvidos para suportar a usabilidade em todos esses contextos. (PETRIE et al., 2015, p. 3)

Nesse sentido, as Tecnologias da Informação e Comunicação (TIC) trazem um grande potencial de inclusão para as pessoas com deficiência ou necessidades educacionais especiais, pois permitem eliminar barreiras, tanto por meio da tecnologia assistiva, quanto pelas potencialidades dos aplicativos e das ferramentas, bem como dos produtos e serviços disponibilizados atualmente. De acordo com Siluk e Pavão (2012, p. 62),

um novo paradigma de educação e formação de professores se estabelece e necessita estar fundamentado em metodologias e práticas educativas inovadoras, responsáveis, que utilizem as tecnologias da informação e comunicação, TIC, de modo a permitir a acessibilidade e a consequente inclusão do aluno nas diversas modalidades de ensino. (SILUK; PAVÃO, 2012, p. 62)

Diante dessa afirmação, entendemos que a superação das dificuldades faz-se necessária. E essa meta poderá ser alcançada se houver a promoção da inclusão social e digital por meio do fornecimento de informações em formatos acessíveis, assegurando que as pessoas com deficiência possam exercer seus direitos, em igualdade de oportunidades com as demais pessoas. Segundo a Lei $n=13.146 / 2015$, consideram-se formatos acessíveis

os arquivos digitais que possam ser reconhecidos e acessados por softwares leitores de telas ou outras tecnologias assistivas que vierem a substituí-los, permitindo leitura com voz sintetizada, ampliação de caracteres, diferentes contrastes e impressão em Braille. (BRASIL, 2015).
(C) ETD- Educação Temática Digital Campinas, SP
v. 20 n.4
p.1117-1137
out./dez. 2018 
Entende-se, portanto, que a acessibilidade digital não se refere apenas ao acesso à informação por meio das TIC, mas também à eliminação de barreiras de comunicação. Sendo assim, a democratização da informação e do conhecimento passou a ganhar maior espaço na sociedade, o que pressupõe ampliar o acesso ao conhecimento ao maior número de pessoas possível, em igualdade de oportunidades e de condições e respeitando o direito à informação. Nessa linha de pensamento, Messa et al. (2011, p. 79) preconiza que

\section{na democracia contemporânea, deveria haver respeito e espaço para a manifestação das minorias, na medida em que o principal pilar de sustentação da democracia consiste no respeito aos direitos fundamentais. (MESSA et al., 2011, p. 79)}

Desse modo, compreendemos que o desenvolvimento da democracia e a participação social dos cidadãos dependem, primeiramente, de acesso, sem barreiras, à informação e ao conhecimento. $E$ isso pode efetivar-se por meio da acessibilidade em documentos digitais, desenvolvidos com base nas orientações de acessibilidade.

\section{ORIENTAÇÕES DE ACESSIBILIDADE}

Existem diretrizes e recomendações de acessibilidade para conteúdos Web. No âmbito internacional, o documento fundamental chama-se Web Content Accessibility Guidelines (WCAG 2.0) - Diretrizes de Acessibilidade para Conteúdo Web, porém diversos países criaram seus próprios documentos, de acordo com a necessidade da sua população. Seguindo esses passos, o governo brasileiro elaborou suas diretrizes e as reuniu em um documento chamado Modelo de Acessibilidade em Governo Eletrônico (eMAG 3.1). Tais Diretrizes de Acessibilidade para Conteúdo Web - WCAG 2.0 foram desenvolvidas pelo World Wide Web Consortium (W3C) por meio do Web Accessibility Initiative (WAI), em colaboração com pessoas e organizações em todo o mundo, com o propósito de fornecer um padrão comum para a acessibilidade do conteúdo Web, que vá ao encontro das necessidades dos indivíduos, das organizações e dos governos, em nível internacional (CALDWELL, et al., 2008).

As WCAG 2.0 compreendem um amplo conjunto de recomendações cujo objetivo é tornar o conteúdo web mais acessível a um maior número de pessoas com deficiência e também mais usável aos utilizadores em geral. Elas são compostas por quatro princípios: perceptível, operável, compreensível e robusto; e doze diretrizes (WCAG, 2008), as quais consistem em um conjunto de recomendações para fazer com que o conteúdo seja acessível, não só para pessoas com deficiência, mas também para os demais usuários, assim como as recomendações do eMAG 3.1.

O Modelo de Acessibilidade do Governo Eletrônico - eMAG 3.1 (2014), tem o compromisso de ser o norteador no desenvolvimento e na adaptação de conteúdos digitais do governo federal, garantindo o acesso a todos. Trata-se de um documento com recomendações a serem consideradas a fim de que o processo de acessibilidade dos sítios e portais do governo brasileiro seja conduzido de forma padronizada e de fácil implementação
(C) ETD- Educação Temática Digital Campinas, SP
v. 20 n.4
p.1117-1137
out./dez. 2018 
(BRASIL, 2014). Essas recomendações são divididas em seções as quais contemplam nove recomendações sobre Marcação, sete recomendações sobre Comportamento, doze recomendações sobre Conteúdo e Informação, quatro recomendações sobre Apresentação e Design, cinco recomendações sobre Multimídia e oito recomendações sobre Formulários, totalizando 45 recomendações (eMAG, 2014). Logo, este estudo analisou as diretrizes e recomendações de acessibilidade WCAG 2.0 e eMAG 3.1 e as adaptou para proporcionar acessibilidade aos documentos digitais criados pelos servidores da universidade pesquisada.

\section{MÉTODO}

Esta é uma pesquisa aplicada, pois teve o propósito de gerar conhecimentos para aplicação prática, direcionados à solução de problemas específicos. Enquanto abordagem, caracteriza-se como qualitativa; quanto aos objetivos, classifica-se como descritiva. E, no que se refere ao tipo, caracteriza-se como estudo de caso. Desse modo, ao investigar sobre como apoiar os servidores, da universidade pesquisada, no processo de criação de documentos digitais acessíveis nos editores de texto Microsoft Word e LibreOffice Writer, buscou-se a solução para um problema coletivo.

Os sujeitos da pesquisa foram os servidores (docentes e técnico-administrativos em educação) de uma Instituição Federal de Ensino Superior (IFES) e alunos com algum tipo de deficiência ou outras necessidades. Como instrumentos para coleta de dados utilizou-se, primeiramente, um questionário on-line com quatro perguntas fechadas e uma pergunta aberta com o objetivo de identificar o grau de conhecimento dos servidores da universidade sobre documentos digitais acessíveis e sobre a importância de ter um manual de orientações para a acessibilidade em documentos digitais.

Após o seu desenvolvimento, o Manual foi disponibilizado aos servidores juntamente com um documento de aplicação das orientações desse manual com instruções de formatação, para que os usuários pudessem avaliar se as orientações estavam claras, com os passos corretos e para que também pudessem sugerir melhorias, registrando suas percepções no questionário de avaliação do manual.

Para validar o manual, foi disponibilizado um documento de validação criado e formatado a partir das orientações do manual a alunos e servidores com alguma deficiência. Eles validaram a acessibilidade do documento registrando suas percepções no questionário de validação.

E para a realização da pesquisa, contemplaram-se os seguintes passos: pesquisa bibliográfica e documental, levantamento de dados, pesquisa de mercado, pesquisa exploratória, desenvolvimento, avaliação, ajuste e validação do manual. 


\section{RESULTADOS E DISCUSSÕES}

\section{Contextualização da pesquisa}

A pesquisa foi realizada em uma universidade do sul do país. No final do ano de 2016, a Instituição tinha aproximadamente 1.757 servidores (902 docentes e 855 técnicoadministrativos em educação), sendo que 19 deles apresentavam alguma deficiência. No mesmo período, havia aproximadamente 11.160 estudantes; e, desses, 1.079 com algum tipo de deficiência ou outras necessidades, conforme o Sistema de Extração de dados da universidade pesquisada.

Dessa forma, os sujeitos deste estudo foram os servidores (docentes e técnicoadministrativos em educação) e os estudantes com algum tipo de deficiência ou outras necessidades. A distribuição do número de estudantes de acordo com o tipo de deficiência encontra-se na Tabela 1.

TABELA 1 - Número de estudantes, conforme o tipo de deficiência

\begin{tabular}{lc}
\hline \multicolumn{1}{c}{ Tipo de deficiência } & № de alunos \\
\hline Baixa visão & 1 \\
Cegueira & 20 \\
Deficiência auditiva & 36 \\
Deficiência física & 2 \\
Deficiência mental & 2 \\
Deficiência múltipla & 37 \\
Deficiência visual & 1 \\
Síndrome de Asperger & 977 \\
\hline Outras necessidades & $\mathbf{1 . 0 7 9}$ \\
\hline TOTAL & \\
\hline
\end{tabular}

Fonte: IFES (2016)

Esses dados representam que a IFES possui aproximadamente $1 \%$ de estudantes com algum tipo de deficiência e quase $9 \%$ com outras necessidades, entretanto não é possível saber se estes estudantes com outras necessidades utilizam Tecnologia Assistiva ou possuem barreiras semelhantes àqueles com deficiência. 
Já a Tabela 2 apresenta o número de estudantes com deficiência ou outras necessidades, considerados evadidos por abandono, cancelamento ou desligamento, no período de 2008 a 2016.

TABELA 2 - Número de estudantes conforme o tipo de deficiência e a forma de evasão

\begin{tabular}{lcccc}
\hline Tipo de deficiência & Abandono & Cancelamento & Desligamento & Total de evadidos \\
\hline Cegueira & 02 & 00 & 00 & $\mathbf{0 2}$ \\
Condutas típicas & 01 & 00 & 00 & $\mathbf{0 1}$ \\
Deficiência auditiva & 18 & 09 & 01 & $\mathbf{2 8}$ \\
Deficiência física & 72 & 15 & 01 & $\mathbf{8 8}$ \\
Deficiência intelectual & 00 & 01 & 00 & $\mathbf{0 1}$ \\
Deficiência mental & 02 & 01 & 00 & $\mathbf{0 3}$ \\
Deficiência múltipla & 05 & 00 & 00 & $\mathbf{0 5}$ \\
Deficiência visual & 45 & 12 & 01 & $\mathbf{5 8}$ \\
Outras necessidades & 1.123 & 339 & 65 & $\mathbf{1 . 5 2 7}$ \\
\hline TOTAL & $\mathbf{1 1 2 6 8}$ & $\mathbf{3 7 7}$ & $\mathbf{6 8}$ & $\mathbf{1 . 7 1 3}$ \\
\hline
\end{tabular}

Fonte: IFES (2016)

Os números indicam que mais de $10 \%$ dos estudantes com algum tipo de deficiência ou outras necessidades evadiram. Esses dados são preocupantes, e a universidade precisa agir no sentido de buscar alternativas para que os estudantes permaneçam na Instituição tendo uma educação de qualidade. Como possibilidade de contribuir com a educação inclusiva na universidade, foi proposto o desenvolvimento do manual de orientações para a criação de documentos digitais acessíveis em editores de texto, a fim de que os servidores tenham conhecimento para criar documentos acessíveis tanto para estudantes, quanto para outros servidores e também para comunidade externa.

Levantamento de dados

O levantamento de dados foi realizado, em novembro de 2016, com o objetivo de identificar o grau de conhecimento dos servidores da universidade sobre documentos digitais acessíveis e a importância de ter um manual de orientações. Como resultado, obtiveram-se os dados iniciais que justificaram o desenvolvimento dos manuais em editores de texto. Do total de 1.757 servidores, 466 responderam ao questionário. Desses, 208 eram docentes e 258 eram técnico-administrativos em educação. 
Sobre a questão de possuir conhecimento para criação de documentos digitais acessíveis, 4\% (18 respondentes) afirmou ter muito conhecimento, 8\% (40 respondentes) respondeu que possui conhecimento, 21\% (96 respondentes) informou ter pouco conhecimento e 67\% (312 respondentes) afirmou não ter conhecimento.

Analisando esses dados, pode-se concluir que $88 \%$ dos respondentes não têm conhecimento ou têm pouco conhecimento para criar documentos digitais acessíveis. E essa falta de conhecimento faz com que eles continuem criando e disponibilizando documentos digitais inacessíveis, afetando assim o acesso à informação e ao conhecimento por parte das pessoas que têm algum tipo de deficiência ou outras necessidades. No Quadro 1, mostra-se o número de servidores que classificaram o grau de importância para criação de documentos digitais acessíveis entre os programas de apresentação, planilha, documento e e-mail.

QUADRO 1 - Questão "Qual a importância de um manual de orientações para criação de documentos digitais acessíveis para os tipos de programas abaixo?"

\begin{tabular}{|c|c|c|c|c|}
\hline Grau de importância & $\begin{array}{c}\text { Editor de } \\
\text { apresentação }\end{array}$ & $\begin{array}{l}\text { Editor de } \\
\text { planilha }\end{array}$ & $\begin{array}{l}\text { Editor de } \\
\text { texto }\end{array}$ & $\begin{array}{c}\text { Gerenciador de e- } \\
\text { mail }\end{array}$ \\
\hline $\begin{array}{l}\text { Extremamente } \\
\text { importante }\end{array}$ & $239(51,3 \%)$ & $227(48,7 \%)$ & $255(54,7 \%)$ & $248(53,2 \%)$ \\
\hline Muito importante & $125(26,8 \%)$ & $134(28,8 \%)$ & $127(27,3 \%)$ & $123(26,4 \%)$ \\
\hline Importante & $90 \quad(19,3 \%)$ & $91(19,5 \%)$ & $76(16,3 \%)$ & $84 \quad(18 \%)$ \\
\hline Pouco Importante & $(1,9 \%)$ & $10 \quad(2,1 \%)$ & $5 \quad(1,1 \%)$ & $(1,5 \%)$ \\
\hline Nada importante & $(0,6 \%)$ & $04 \quad(0,9 \%)$ & $3 \quad(0,6 \%)$ & $04 \quad(0,9 \%)$ \\
\hline
\end{tabular}

Fonte: Dados coletados pela autora.

A partir da análise desses dados, evidenciou-se que a maioria dos respondentes (255) considerou extremamente importante ter um manual com orientações para a criação de documentos digitais acessíveis em editores de texto, assim como a minoria dos servidores (8) indicaram nada importante ou pouco importante a criação desse mesmo manual. Por isso, optou-se por desenvolver manual de orientações para criação de documentos digitais acessíveis em editores de texto.

Além das perguntas fechadas, o questionário apresentou uma pergunta aberta, na qual os servidores puderam se manifestar indicando sugestões, necessidades ou informações complementares. Nessa pergunta, comprovou-se que ter um manual que oriente sobre a acessibilidade em documentos digitais é considerado extremamente importante, conforme foi citado na pesquisa na qual um respondente declarou que:

\footnotetext{
C ETD- Educação Temática Digital Campinas, SP

v.20 n.4

p.1117-1137

out./dez. 2018
} 


\begin{abstract}
Ter um manual com orientações para criação de documentos digitais acessíveis é de extrema importância tanto para docentes quanto para TAEs, pois assim alunos, servidores e comunidade em geral serão beneficiadas, tendo acesso a toda informação e conhecimento criada e disponibilizada pela universidade. (Respondente 1).
\end{abstract}

Percebe-se também que alguns servidores não faziam ideia da possibilidade de criar documentos acessíveis, conforme outros dois respondentes:

Pesquisa importante, não fazia ideia dessas opções! (Respondente 2).

Nunca tive a "necessidade" de utilizar estas ferramentas acessíveis. A partir da sua pesquisa percebi que sou leiga no assunto e que ficaria totalmente perdida para trabalhar com pessoas que necessitassem desses recursos (Respondente 3 ).

Portanto, alguns servidores consideraram esta pesquisa bastante relevante, sendo que o objetivo deste estudo é desenvolver um manual de orientações para a criação de documentos digitais acessíveis.

\title{
Pesquisa de mercado
}

A pesquisa de mercado foi realizada para identificar os manuais de orientações para criação de documentos digitais acessíveis existentes e disponíveis na internet. Como resultado, encontraram-se cinco manuais, sendo o primeiro, denominado "Um guia prático para tornar documentos acessíveis: parte I", que contempla acessibilidade em documentos do Microsoft Word 2013 e PDF e foi criado por Fortes et al. (2015). Já Salton (2017) desenvolveu "Criando documentos digitais acessíveis Word, PowerPoint e PDF", que aborda acessibilidade em Microsoft Word e PowerPoint nas versões 2003, 2007 e 2010 e PDF.

O terceiro manual foi desenvolvido por Silva e Sacramento (2017) chama-se "Orientações para criação de documentos acessíveis no Microsoft Word", e compreende acessibilidade em documentos Microsoft Word 2013 e PDF. Cmuchal (2015) criou "Linhas de orientação para informação acessível. Tic para a acessibilidade à informação na aprendizagem", o qual descreve dicas de como tornar acessível informação textual, imagem, áudio, vídeo, documentos eletrônicos, recursos online e material impresso, sem indicar como aplicar essas dicas em programas específicos.

O último material encontrado foi desenvolvido por Sonza et al. (2015) e denomina-se "O uso pedagógico dos recursos de tecnologia assistiva", sendo que o capítulo V desse livro aborda recursos pedagógicos acessíveis e descreve acessibilidade em arquivos do Microsoft Office Word, PowerPoint, documentos PDF, documentos digitalizados e acessibilidade de conteúdos multimídia - Áudio e Vídeo.

Após a leitura desses documentos, percebeu-se a necessidade de desenvolver um manual que contemplasse a acessibilidade em documentos criados no LibreOffice Writer e

(C) ETD- Educação Temática Digital Campinas, SP $\quad$ v.20 n.4 p.1117-1137 out./dez. 2018


Microsoft Word, pois, mesmo existindo manuais desses programas, eles não contemplam todas as recomendações sugeridas e suas instruções voltam-se à utilização do botão direito do mouse, então, um dos diferenciais foi orientar a aplicação dos recursos com o uso do teclado, utilizando as teclas de atalho e o mouse. Além disso, esses programas são significativamente utilizados pelos servidores da universidade pesquisada para criação de documentos digitais.

\section{Pesquisa exploratória}

A pesquisa exploratória foi realizada para definir as orientações para a criação de documentos digitais acessíveis utilizadas no manual. Para isso, as diretrizes WCAG 2.0 e as recomendações eMAG 3.1, sobre acessibilidade Web, foram adaptadas de Duarte e Rocha (2012), sendo comparadas com os recursos disponíveis nos editores de texto. Dessa forma, elaborou-se a terceira coluna do quadro, com as adaptações a documentos digitais, conforme Quadro 2.

QUADRO 2 - Comparação entre WCAG 2.0 e eMAG 3.1 e adaptações a documentos digitais

\begin{tabular}{|c|c|c|}
\hline DIRETRIZES WCAG 2.0 & RECOMENDAÇÕES EMAG 3.1 & $\begin{array}{c}\text { ADAPTAÇÕES A DOCUMENTOS } \\
\text { DIGITAIS }\end{array}$ \\
\hline $\begin{array}{l}\text { 1.1 Fornecer alternativas } \\
\text { em texto para todo o } \\
\text { conteúdo não textual de } \\
\text { modo que ele possa ser } \\
\text { apresentado de outras } \\
\text { formas, de acordo com as } \\
\text { necessidades dos } \\
\text { usuários. }\end{array}$ & $\begin{array}{l}\text { 3.6 Fornecer alternativa em texto para } \\
\text { as imagens do sítio; } \\
\text { 3.7 Utilizar mapas de imagem de forma } \\
\text { acessível; } \\
\text { 6.1 Fornecer alternativa em texto para } \\
\text { os botões de imagem de formulários; } \\
\text { 6.2 Associar etiquetas aos seus campos; } \\
\text { 6.8 Fornecer estratégias de segurança } \\
\text { específicas ao invés de CAPTCHA. }\end{array}$ & Uso de elementos não textuais \\
\hline $\begin{array}{l}1.2 \text { Fornecer alternativas } \\
\text { para conteúdo em } \\
\text { multimídia dinâmica ou } \\
\text { temporal. }\end{array}$ & $\begin{array}{l}\text { 5.1 Fornecer alternativa para vídeo; } \\
\text { 5.2 Fornecer alternativa para áudio; } \\
\text { 5.3 Oferecer audiodescrição para vídeo } \\
\text { pré-gravado; } \\
\text { 5.4 Fornecer controle de áudio para } \\
\text { som. }\end{array}$ & $\begin{array}{l}\text { Esta diretriz e recomendações não } \\
\text { serão adaptadas, pois nos programas } \\
\text { editores de texto não costumam ser } \\
\text { incluídos conteúdos multimídia. }\end{array}$ \\
\hline $\begin{array}{l}\text { 1.3 Criar conteúdo que } \\
\text { possa ser apresentado de } \\
\text { diferentes formas sem } \\
\text { perder informação ou } \\
\text { estrutura. }\end{array}$ & $\begin{array}{l}\text { 1.2 Organizar o código HTML de forma } \\
\text { lógica e semântica; } \\
\text { 1.6 Não utilizar tabelas para } \\
\text { diagramação; } \\
\text { 3.9 Em tabelas, utilizar títulos e resumos } \\
\text { de forma apropriada. } \\
\text { 3.10 Associar células de dados às células } \\
\text { de cabeçalho; } \\
\text { 6.7 Agrupar campos de formulário; }\end{array}$ & $\begin{array}{l}\text { Uso de tabelas } \\
\text { Uso de colunas }\end{array}$ \\
\hline
\end{tabular}

(C) ETD-Educação Temática Digital Campinas, SP

v. 20 n.4

p.1117-1137

out./dez. 2018 


\begin{tabular}{|c|c|c|}
\hline $\begin{array}{l}\text { 1.4 Facilitar aos usuários a } \\
\text { audição e a visualização } \\
\text { dos conteúdos por meio } \\
\text { da separação do primeiro } \\
\text { plano do plano de fundo. }\end{array}$ & $\begin{array}{l}\text { 4.1 Oferecer contraste mínimo entre } \\
\text { plano de fundo e primeiro plano; } \\
4.2 \text { Não utilizar apenas cor ou outras } \\
\text { características sensoriais para } \\
\text { diferenciar elementos; } \\
\text { 4.3 Permitir redimensionamento sem } \\
\text { perda de funcionalidade. }\end{array}$ & $\begin{array}{l}\text { Uso da cor } \\
\text { Uso das margens } \\
\text { Uso do alinhamento do texto } \\
\text { Uso do espaçamento entre linhas e } \\
\text { entre parágrafos } \\
\text { Uso das listas com marcadores e } \\
\text { numeração }\end{array}$ \\
\hline $\begin{array}{l}2.1 \text { Fazer com que toda a } \\
\text { funcionalidade fique } \\
\text { disponível a partir do } \\
\text { teclado. }\end{array}$ & $\begin{array}{l}\text { 2.1 Disponibilizar todas as funções da } \\
\text { página via teclado; }\end{array}$ & $\begin{array}{l}\text { Os programas editores de texto } \\
\text { possuem teclas de atalho próprias } \\
\text { para acessar as funcionalidades, } \\
\text { então o manual fornecerá orientações } \\
\text { de como aplicar as orientações } \\
\text { utilizando o teclado e o mouse. }\end{array}$ \\
\hline $\begin{array}{l}2.2 \text { Proporcionar aos } \\
\text { usuários tempo suficiente } \\
\text { para lerem e utilizarem o } \\
\text { conteúdo. }\end{array}$ & $\begin{array}{l}\text { 2.5 Fornecer alternativa para modificar } \\
\text { limite de tempo; } \\
\text { 2.7 Assegurar o controle do usuário } \\
\text { sobre as alterações temporais do } \\
\text { conteúdo; } \\
\text { 5.5 Fornecer controle de animação. }\end{array}$ & $\begin{array}{l}\text { Esta diretriz e recomendações não } \\
\text { serão adaptadas, pois os programas } \\
\text { editores de texto não possuem } \\
\text { recursos para controle de tempo. }\end{array}$ \\
\hline $\begin{array}{l}2.3 \text { Não criar conteúdo de } \\
\text { uma forma que se sabe } \\
\text { que pode causar } \\
\text { convulsões. }\end{array}$ & $\begin{array}{l}2.6 \text { Não incluir situações com } \\
\text { intermitência de tela. }\end{array}$ & Uso do tipo e tamanho da fonte \\
\hline $\begin{array}{l}\text { 2.4 Fornecer formas de } \\
\text { ajudar os usuários a } \\
\text { navegar, localizar } \\
\text { conteúdos e determinar o } \\
\text { local onde estão. }\end{array}$ & $\begin{array}{l}\text { 1.3 Utilizar corretamente os níveis de } \\
\text { cabeçalho; } \\
\text { 1.4 Ordenar de forma lógica e intuitiva a } \\
\text { leitura e tabulação; } \\
\text { 1.5 Fornecer âncoras para ir direto a um } \\
\text { bloco de conteúdo; } \\
\text { 1.7 Separar links adjacentes; } \\
\text { 1.8 Dividir as áreas de informação; } \\
\text { 3.3 Oferecer um título descritivo e } \\
\text { informativo à página; } \\
\text { 3.4 Informar o usuário sobre sua } \\
\text { localização na página; } \\
\text { 3.5 Descrever links clara e sucintamente; } \\
\text { 4.4 Possibilitar que o elemento com foco } \\
\text { seja visualmente evidente; } \\
\text { 6.3 Estabelecer uma ordem lógica de } \\
\text { navegação. }\end{array}$ & $\begin{array}{l}\text { Uso dos estilos para formatar títulos } \\
\text { Uso de número de página } \\
\text { Uso do sumário automático } \\
\text { Uso do índice de ilustrações } \\
\text { Uso de hiperlinks } \\
\text { Uso da quebra de página e quebra de } \\
\text { seção }\end{array}$ \\
\hline
\end{tabular}




\begin{tabular}{|c|c|c|}
\hline $\begin{array}{l}3.1 \text { Tornar o conteúdo } \\
\text { textual legível e } \\
\text { compreensível. }\end{array}$ & $\begin{array}{l}\text { 3.1 Identificar o idioma principal da } \\
\text { página; } \\
\text { 3.2 Informar mudança de idioma no } \\
\text { conteúdo; } \\
\text { 3.11 Garantir a leitura e a compreensão } \\
\text { das informações; } \\
\text { 3.12 Disponibilizar uma explicação para } \\
\text { siglas, abreviaturas e palavras incomuns. }\end{array}$ & $\begin{array}{l}\text { Uso do idioma do documento } \\
\text { Uso de lista de siglas e abreviaturas }\end{array}$ \\
\hline $\begin{array}{l}\text { 3.2 Fazer com que as } \\
\text { páginas Web apareçam e } \\
\text { funcionem de forma } \\
\text { previsível. }\end{array}$ & $\begin{array}{l}\text { 1.9 Não abrir novas instâncias sem a } \\
\text { solicitação do usuário; } \\
\text { 2.2 Garantir que os objetos } \\
\text { programáveis sejam acessíveis. } \\
\text { 2.3 Não criar páginas com atualização } \\
\text { automática periódica; } \\
\text { 2.4 Não utilizar redirecionamento } \\
\text { automático de páginas; } \\
\text { 6.4 Não provocar automaticamente } \\
\text { alteração no contexto. }\end{array}$ & $\begin{array}{l}\text { Esta diretriz e recomendações não } \\
\text { serão adaptadas, pois os programas } \\
\text { editores de texto não provocam } \\
\text { atualizações automáticas. }\end{array}$ \\
\hline $\begin{array}{l}\text { 3.3 Ajudar os usuários a } \\
\text { evitar e a corrigir os erros. }\end{array}$ & $\begin{array}{l}\text { 6.5 Fornecer instruções para entrada de } \\
\text { dados; } \\
6.6 \text { Identificar e descrever erros de } \\
\text { entrada de dados e confirmar o envio } \\
\text { das informações. }\end{array}$ & $\begin{array}{l}\text { Uso da ortografia e da gramática } \\
\text { Uso da Ajuda }\end{array}$ \\
\hline $\begin{array}{l}\text { 3.4 Maximizar a } \\
\text { compatibilidade com os } \\
\text { agentes de usuário atuais } \\
\text { e futuros, incluindo as } \\
\text { tecnologias assistivas. }\end{array}$ & 1.1 Respeitar os Padrões Web. & Uso da verificação de acessibilidade \\
\hline $\begin{array}{l}\text { Não há diretriz } \\
\text { correspondente a essa } \\
\text { recomendação. }\end{array}$ & $\begin{array}{l}\text { 3.8 Disponibilizar documentos em } \\
\text { formatos acessíveis. }\end{array}$ & $\begin{array}{l}\text { Uso da propriedade do documento } \\
\text { Uso do salvar }\end{array}$ \\
\hline
\end{tabular}

Fonte: adaptado de Duarte e Rocha (2012)

A partir dessa comparação, foram estabelecidas as adaptações para documentos digitais, e o manual foi desenvolvido.

Desenvolvimento do manual

O desenvolvimento do manual de orientações para criação de documentos digitais acessíveis em editores de texto partiu da pesquisa exploratória, em que foram comparadas as diretrizes WCAG 2.0 e as recomendações eMAG 3.1 a fim de definir as orientações para documentos digitais. Tendo a definição de 22 orientações, elaborou-se o passo a passo de como aplicá-las, utilizando-se o teclado, o mouse e ilustrações com prints das telas dos programas. Sendo assim, o documento ficou mais acessível, pois poderá ser acessado por 
pessoas que utilizam apenas o teclado, ou somente o mouse, ou tem um melhor entendimento visualizando imagens.

Além disso, aplicaram-se as 22 orientações para que o manual ficasse acessível ao maior número de pessoas, tais como: tipo de letra sem serifa, tamanho da fonte adequado, cor com um bom contraste, alinhamento à esquerda, espaçamento entre linhas e entre parágrafos que facilitam a leitura, lista com marcadores nas instruções, uso de estilos nos títulos, margens de acordo com o padrão, quebra de página e de seção para evitar linhas em branco, uso de tabelas com a formatação adequada, elementos não textuais com título, descrição e legenda, inserção de número de páginas, sumário, índice de ilustrações, verificação do idioma, de ortografia e gramática, inclusão das propriedades do documento, disponibilização em diferentes formatos e verificação da acessibilidade.

Para descrever as 99 imagens do manual, foi solicitada a opinião de uma consultora da comissão de audiodescrição de uma IFES do sul do país, de um consultor cego de uma IFES do sul do país e de uma consultora do projeto Livro Acessível. Para isso, aos consultores foi enviada uma parte do manual com descrições das imagens baseadas no entendimento da pesquisadora. Conforme a Nota Técnica no 21 de 2012,

a descrição de imagens é a tradução em palavras, a construção de retrato verbal de pessoas, paisagens, objetos, cenas e ambientes, sem expressar julgamento ou opiniões pessoais a respeito. (BRASIL, 2012).

Assim, a partir das opiniões dos consultores, melhoraram-se as descrições das imagens, incluíram-se legendas e fontes, atendendo também a Nota Técnica no 005 de 2011, sobre as imagens, no livro digital acessível - Mecdaisy, [...] A legenda, fonte ou informações sobre a origem da imagem devem ser apresentadas posteriormente à descrição e à apresentação da própria imagem (BRASIL, 2011).

Então, após o desenvolvimento do manual de orientações para criação de documentos digitais acessíveis nos editores de texto Microsoft Word 2010 e LibreOffice Writer, foi realizada a validação automática de acessibilidade do documento, por meio do recurso verificar acessibilidade do Word, sendo que essa é uma recomendação do eMAG (2014):

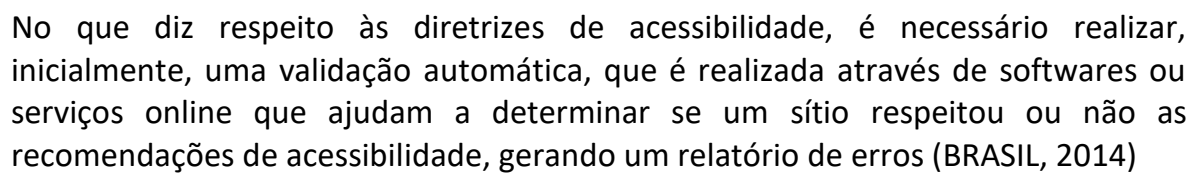

Salienta-se que, para uma validação mais efetiva, enviou-se o manual a um consultor cego para que fizesse a validação manual de acessibilidade e, posteriormente, realizaram-se os ajustes. A disponibilização do manual foi realizada por e-mail nos formatos. odt, .doc e .pdf. 
Avaliação e ajuste do manual

A avaliação do manual foi realizada pelos servidores da IFES pesquisada, em maio de 2017, com o objetivo de verificarem a clareza das orientações, as dificuldades encontradas na sua utilização e também para apontarem sugestões de melhoria. O convite foi enviado por email, juntamente com o manual de orientações, com o questionário de avaliação e com o documento de aplicação das orientações do manual com instruções de formatação.

Os servidores escolheram o editor de texto de sua preferência e realizaram a formatação do documento conforme orientações. Ao total, 29 servidores fizeram a avaliação, 6 docentes e 23 técnico-administrativos em educação.

Observou-se que o editor de texto pelo qual os servidores têm mais conhecimento é o Word, sendo essa uma realidade nas instituições, assim como afirmam Simão e Nomura (2014, p. 1), "O Word é um dos processadores de texto mais utilizados e mais populares, detendo na prática, o monopólio da criação de documentos na maioria das instituições públicas e privadas". Porém, a IFES pesquisada, por meio do Plano Diretor de Tecnologia da Informação e Comunicação 2017-2019 (2016), tem como objetivos "Fomentar a disponibilização e o uso de dados abertos" e "Incentivo ao uso de softwares livres". Nesse sentido, algumas ações estão sendo realizadas, como a capacitação de servidores para o uso do LibreOffice e a instalação de software livre nos computadores da universidade. O resultado disso pode ser percebido pela escolha do programa para realizar a avaliação, sendo que houve um crescimento na utilização do Writer em comparação ao grau de conhecimento que os servidores têm sobre esse editor de texto, pois oito servidores (28\%) informaram que têm conhecimento sobre o Writer, enquanto 12 servidores (41\%) utilizaram o Writer para realizar a avaliação do manual.

Além das perguntas fechadas, o questionário apresentou algumas questões abertas, entre elas: Quais as suas sugestões para melhorar o manual? Tendo como base as dificuldades encontradas pelos servidores e sugestões de melhoria, realizaram-se os ajustes, conforme Quadro 3. 
QUADRO 3 - Avaliação: sugestões e ajustes

\begin{tabular}{|c|c|}
\hline SUGESTÕES & AJUSTES REALIZADOS \\
\hline Identificar a versão do Editor Writer usada. & $\begin{array}{l}\text { A versão do Writer usada foi identificada no início das } \\
\text { orientações do manual. }\end{array}$ \\
\hline $\begin{array}{l}\text { No item } 2.4 \text { cita-se espaçamento } 2,25 \text { e depois em } \\
0,10 \mathrm{~cm} \text {. }\end{array}$ & Este item foi corrigido. \\
\hline $\begin{array}{l}\text { Fazer vídeos curtos implementando as formações } \\
\text { sugeridas. }\end{array}$ & Esta será uma sugestão para trabalhos futuros. \\
\hline $\begin{array}{l}\text { Separar as temáticas, o usuário escolhe qual arquivo } \\
\text { irá ler e navegar conforme o software que irá usar. }\end{array}$ & $\begin{array}{l}\text { O manual, que era um arquivo dividido em duas } \\
\text { partes, passou a ser dois arquivos, um manual do } \\
\text { Word e um manual do Writer. }\end{array}$ \\
\hline $\begin{array}{l}\text { Fornecer ele em diversas plataformas, como em } \\
\text { HTML, pois é fácil de navegar, disponibilizar online } \\
\text { para futuras consultas. }\end{array}$ & $\begin{array}{l}\text { O manual será disponibilizado em .pdf, .odt e .doc } \\
\text { para download e em .html no site da IFES, atendendo } \\
\text { as diretrizes de acessibilidade Web. }\end{array}$ \\
\hline $\begin{array}{l}\text { Deixar mais enxuto, as normas da ABNT são ótimas } \\
\text { para trabalhos científicos, mas deixa o texto longo } \\
\text { com um número absurdo de páginas, disponibilize } \\
\text { uma versão mais informal, com links de ligação entre } \\
\text { o índice até a página do assunto. }\end{array}$ & $\begin{array}{l}\text { Por uma questão de acessibilidade, optou-se em } \\
\text { manter o manual com as normas, pois os recursos de } \\
\text { sumário, índice, legenda, fonte, entre outros facilitam } \\
\text { a navegação e leitura do documento. Ele já está com } \\
\text { links. }\end{array}$ \\
\hline Ampliar informações no que se refere à tabela. & Foram ampliadas as informações referentes à tabela. \\
\hline
\end{tabular}

Fonte: Dados coletados pela autora.

Considera-se que as sugestões e os ajustes foram importantes para melhorar a qualidade e a compreensão do manual, e evidencia-se que $93 \%$ dos servidores participantes da avaliação ficaram satisfeitos ou muito satisfeitos com o manual, e $7 \%$ dos participantes permaneceram indiferentes. Portanto, o manual é um recurso útil que auxiliará as pessoas a criarem documentos digitais acessíveis, mas é importante ter uma política institucional para que todos os documentos criados e disponibilizados sejam acessíveis.

\section{Validação e ajuste do manual}

Após a avaliação e ajustes do manual, a pesquisadora criou um documento de validação, formatado de acordo com as orientações do manual e elaborou um questionário de validação para que, após a leitura do documento, as pessoas com deficiência registrassem suas percepções sobre a acessibilidade do documento.

O documento e o questionário de validação foram respondidos, em maio de 2017, por quatro estudantes da universidade pesquisada, com diferentes tipos de deficiência (deficiência visual, deficiência física, paralisia cerebral e baixa visão), por uma docente surda e um consultor cego. Dessa forma, participaram da validação pessoas dos diferentes

\footnotetext{
(C) ETD- Educação Temática Digital Campinas, SP

v. 20 n. 4

p.1117-1137

out./dez. 2018
} 
segmentos (docente, técnico-administrativo em educação e estudantes), com diversas deficiências, o que foi fundamental para a validação do manual.

Entre as questões do questionário de validação, foram solicitadas sugestões ou comentários sobre o documento de validação, desse modo, apresentam-se as sugestões/comentários e ajustes no Quadro 4.

QUADRO 4 - Validação: sugestões/comentários e ajustes

\begin{tabular}{|l|l|}
\hline \multicolumn{1}{|c|}{ SUGESTÕES/COMENTÁRIOS } & \multicolumn{1}{|c|}{ AJUSTES REALIZADOS } \\
\hline $\begin{array}{l}\text { Comentário: Uma coisa que peço para ser colocada em } \\
\text { provas, assim ficando mais tranquilo de ser lida é a } \\
\text { colocação do texto em negrito, deixando mais legível o } \\
\text { entendimento. Já em documentos digitais, não precisa } \\
\text { deste adicional e o texto normal já fica legível. }\end{array}$ & Sem necessidade de ajustes. \\
\hline $\begin{array}{l}\text { Sugestão: Nas descrições das imagens, coloque } \\
\text { "Descrição da imagem" no início, para entendermos } \\
\text { que a frase tem essa função. }\end{array}$ & $\begin{array}{l}\text { Foi inserido "Descrição da imagem" como título da } \\
\text { descrição das 99 imagens do manual. }\end{array}$ \\
\hline $\begin{array}{l}\text { Sugestão: Indicar a disponibilização do arquivo em PDF } \\
\text { para evitar problemas nas versões de editores de } \\
\text { texto. }\end{array}$ & $\begin{array}{l}\text { Foi inserido no manual o passo a passo com } \\
\text { ilustrações de como salvar ou exportar em PDF e foi } \\
\text { orientada a importância da disponibilização nesse } \\
\text { formato. }\end{array}$ \\
\hline $\begin{array}{l}\text { Comentário: Só preciso usar com legenda ou janela de } \\
\text { intérprete de Libras. }\end{array}$ & $\begin{array}{l}\text { Todas as imagens do manual possuem legenda. } \\
\text { Quando o manual for disponibilizado em html na } \\
\text { página da IFES poderá usar o recurso VLibras. }\end{array}$ \\
\hline
\end{tabular}

Fonte: Dados coletados pela autora.

A validação manual é um dos passos sugeridos pelo eMAG (2014) para a avaliação de acessibilidade, conforme podemos conferir:

\begin{abstract}
A validação manual é uma etapa essencial na avaliação de acessibilidade de um sítio, já que os validadores automáticos não são capazes de detectar todos os problemas de acessibilidade em um sítio, pois muitos aspectos requerem um julgamento humano. Por exemplo, validadores automáticos conseguem detectar se o atributo para descrever imagens foi utilizado em todas as imagens do sítio, mas somente uma pessoa poderá verificar se a descrição da imagem está adequada ao seu conteúdo. [...] (BRASIL, 2014).
\end{abstract}

Tendo em vista a importância da validação do manual, a etapa de testes com usuários reais (pessoas com deficiência) é considerada fundamental, pois de acordo com eMAG (2014), "Um usuário real poderá dizer se um sítio está realmente acessível, compreensível e com boa usabilidade e não simplesmente tecnicamente acessível". Esse processo de validação manual com a participação de usuários com deficiência foi muito importante para garantir que o manual oriente corretamente para a criação de documentos digitais acessíveis.

\author{
(C) ETD- Educação Temática Digital Campinas, SP \\ v. 20 n.4 \\ p.1117-1137 \\ out./dez. 2018
}




\section{CONSIDERAÇÕES FINAIS}

A acessibilidade dos documentos digitais pode ser compreendida como uma forma de democratização, em que se amplia o acesso à informação e ao conhecimento. Nessa perspectiva, as tecnologias podem ser instrumentos aliados a uma prática educativa mais inclusiva. Assim, um sistema educacional inclusivo, demanda a articulação de ações que garantam o direito de pessoas com deficiência a não apenas ingressarem nos espaços regulares de ensino, mas também de terem condições de permanecer neles e concluir os seus estudos de forma efetiva.

Nesse sentido, a acessibilidade dos documentos digitais é uma das ações necessárias para a concretização de processos inclusivos no ensino superior, já que os estudantes com deficiência, incluídos nesses espaços, precisam de um conjunto de elementos que auxiliem na aprendizagem e no desenvolvimento acadêmico, dentre esses, o acesso a documentos digitais criados e disponibilizados pelas instituições.

Desta forma, entre as contribuições da pesquisa, citam-se: a conscientização das pessoas acerca da acessibilidade dos materiais a serem produzidos e veiculados pela IFES, pois a maioria dos servidores não tinha consciência da importância e nem sabia como fazer para que os documentos fossem acessíveis; o desenvolvimento do manual e a avaliação dos servidores, considerando-o como material de apoio importante para a criação de documentos digitais acessíveis, tendo em vista a quantidade de alunos com deficiência e o elevado número de evasões na instituição; o manual pode ser referenciado em documentos orientadores ou normativos, como os de elaboração de monografias, dissertações e teses.

Entre as limitações da pesquisa, por sua vez, destaca-se que a validação do manual foi realizada apenas no editor de texto Microsoft Word, pois as pessoas com deficiência não tinham conhecimento e não usavam o LibreOffice Writer para testar a acessibilidade do documento disponibilizado por meio desse software. Porém, de acordo com sugestão do consultor cego, o ideal é disponibilizar o documento em PDF acessível, assim se evita problemas relacionados aos editores de texto e versões utilizadas.

Desse modo, apresentam-se perspectivas de trabalhos futuros, algumas delas extraídas das próprias sugestões dos servidores, como, por exemplo, o desenvolvimento de vídeos curtos com a explicação de cada orientação para tornar documentos digitais acessíveis, utilizando-se legenda e intérprete de Libras; o desenvolvimento de manuais para criação de documentos digitais acessíveis em outros programas, como apresentações e planilhas; a capacitação aos servidores, por meio de cursos práticos; e a disponibilização do manual em formato html no site da Instituição, atendendo às diretrizes e recomendações de acessibilidade para páginas Web. 
No entanto, ainda é possível realizar outras ações como: avaliar se a utilização do manual contribuiu para a criação de documentos mais acessíveis no cotidiano da universidade; de que modo poderia se expandir a criação de documentos acessíveis; se os servidores da IFES utilizam o manual e se há outras iniciativas.

Concluindo, é possível afirmar que o manual apresenta potencial para apoiar a criação de documentos digitais mais acessíveis e considera-se imprescindível que as instituições continuem trabalhando para desenvolverem estratégias que favoreçam os processos inclusivos em seus espaços para que a democratização do conhecimento seja uma realidade possível.

\section{REFERÊNCIAS}

AMORIM, Joni; SILVA, Mariana da Rocha. Produção de multimídia e acessibilidade em cursos de aprendizagem a distância. ETD - Educação Temática Digital, Campinas, v.10, n.2, p.355372, jun. 2009 - ISSN: 1676-2592. Disponível em:

https://periodicos.sbu.unicamp.br/ojs/index.php/etd/article/view/993 . Acesso em: 10 ago. 2017.

BRASIL. Constituição da República Federativa do Brasil (1988). Promulgada em 05 de outubro de 1988. Disponível em:

http://www.planalto.gov.br/ccivil 03/constituicao/constituicao.htm . Acesso em: 16 ago. 2017.

BRASIL. Decreto № 7.611, de 17 de Novembro de 2011. Dispõe sobre a educação especial, o atendimento educacional especializado e dá outras providências. Disponível em:

http://www.planalto.gov.br/ccivil 03/ ato2011-2014/2011/decreto/d7611.htm . Acesso em: 17 ago. 2017.

BRASIL. Lei $n$ ㅇ 12.527, de 18 de novembro de 2011. Regula o acesso a informações previsto no inciso XXXIII do art. 5o, no inciso II do § 30 do art. 37 e no § 20 do art. 216 da Constituição Federal; altera a Lei no 8.112, de 11 de dezembro de 1990; revoga a Lei no 11.111, de 5 de maio de 2005, e dispositivos da Lei no 8.159, de 8 de janeiro de 1991; e dá outras providências. Brasília, 2011. Disponível em:

http://www.planalto.gov.br/ccivil 03/ ato2011-2014/2011/lei/l12527.htm Acesso em: 14 ago. 2017.

BRASIL. Lei no 13.146, de 6 de julho de 2015. Institui a Lei Brasileira de Inclusão da Pessoa com Deficiência (Estatuto da Pessoa com Deficiência). Brasília, 2015. Disponível em: http://www.planalto.gov.br/ccivil 03/ ato2015-2018/2015/Lei/L13146.htm Acesso em: 08 ago. 2017.

BRASIL. Lei no 13.409, de 28 de dezembro de 2016. Altera a Lei no 12.711, de 29 de agosto de 2012, para dispor sobre a reserva de vagas para pessoas com deficiência nos cursos técnico de nível médio e superior das instituições federais de ensino. Disponível em: http://www.planalto.gov.br/ccivil 03/ ato2015-2018/2016/lei/L13409.htm - Acesso em: 17 ago. 2017.

(C) ETD- Educação Temática Digital Campinas, SP $\quad$ v.20 n.4 $\quad$ p.1117-1137 $\quad$ out./dez. 2018 
BRASIL. Nota Técnica no 005 / 2011 / MEC / SEESP / GAB. Publicação em formato digital acessível - Mecdaisy. Disponível em:

http://portal.mec.gov.br/index.php?option=com docman\&view=download\&alias=9959nota-tecnica-05-2011-secadi\&category slug=fevereiro-2012-pdf\&Itemid=30192 . Acesso em: 10 ago. 2017.

BRASIL Nota Técnica no 21 / 2012 / MEC / SECADI / DPEE. Orientações para descrição de imagem na geração de material digital acessível - Mecdaisy. Disponível em:

http://portal.mec.gov.br/index.php?option=com docman\&view=download\&alias=10538nota-tecnica-21-mecdaisy-pdf\&category slug=abril-2012-pdf\&Itemid=30192 . Acesso em: 10 ago. 2017.

BRASIL. eMAG - Modelo de Acessibilidade em Governo Eletrônico. versão 3.1 - Abril 2014. Disponível em: http://emag.governoeletronico.gov.br/ . Acesso em: 16 ago. 2017.

CALDWELL, Ben et al. (Ed.). Diretrizes de Acessibilidade para Conteúdo Web (WCAG) 2.0. Recomendação W3C de 11 de dezembro de 2008. Disponível em:

http://www.w3.org/translations/wcag20-pt-pt/. Acesso em: 10 ago. 2017.

CMUCHAL, Marcella Turner. Linhas de orientação para informação acessível Tic para a acessibilidade à informação na aprendizagem (ICT4IAL). Agência Europeia para as Necessidades Especiais e a Educação Inclusiva, 2015. Disponível em:

https://www.european-

agency.org/sites/default/files/Guidelines\%20for\%20Accessible\%20Information PT.pdf .

Acesso em: 05 jul. 2017

DUARTE, Adriana Bogliolo Sirihal; ROCHA, Janicy Aparecida Pereira. Diretrizes de acessibilidade web: um estudo comparativo entre as WCAG 2.0 e o e-MAG 3.0. Inc. Soc., Brasília, DF, v. 5 n. 2, p.73-86, jan./jun. 2012. Disponível em:

http://revista.ibict.br/inclusao/article/view/1678/1884 . Acesso em: 10 ago. 2017.

FORTES, Renata et al. Um guia prático para tornar documentos acessíveis: parte I. Universidade de São Paulo. Instituto de Ciências Matemáticas e de Computação. Departamento de Ciências da Computação. 2015. Disponível em: http://conteudo.icmc.usp.br/CMS/Arquivos/arquivos enviados/BIBLIOTECA 158 ND 95.pd f. Acesso em: 18 jul. 2017.

GUERREIRO, Elaine Maria Bessa Rebello. A acessibilidade e a educação: um direito constitucional como base para um direito social da pessoa com deficiência. Revista Educação Especial, Santa Maria, v. 25, n. 43, p. 217-232, maio/ago. 2012. Disponível em: https://periodicos.ufsm.br/educacaoespecial/article/view/4415 . Acesso em: 16 jul. 2017.

INSTITUTO NACIONAL DE ESTUDOS E PESQUISAS EDUCACIONAIS ANÍSIO TEIXEIRA. Sinopse estatística da educação superior 2015. Brasília: Inep, 2016. Disponível em: http://portal.inep.gov.br/web/guest/sinopses-estatisticas-da-educacao-superior . Acesso em: 15 ago. 2017.

(C) ETD- Educação Temática Digital Campinas, SP $\quad$ v.20 n.4 $\quad$ p.1117-1137 $\quad$ out./dez. 2018 
MESSA, Ana Flávia; NETO, Nuncio Theophilo; JUNIOR, Roque Theophilo (Coord.).

Sustentabilidade ambiental e os novos desafios na era digital: estudos em homenagem a Benedito Guimarães Neto. São Paulo: Saraiva, 2011.

PEREIRA, Rosamaria Reo; SILVA, Souza da Costa Silva; FACIOLA, Rosana Assef; PONTES, Fernando Augusto Ramos; RAMOS, Maély Ferreira Holanda. Inclusão de estudantes com deficiência no ensino superior: uma revisão sistemática. Revista Educação Especial, v. 29, n. 54, p. 147-160, jan./abr. 2016, Santa Maria. Disponível em:

https://periodicos.ufsm.br/educacaoespecial/article/view/19898 . Acesso em: 16 jul. 2017.

PETRIE, Helen; SAVVA, Andreas; POWER, Christopher. Towards a unified definition of web accessibility. In: PROCEEDINGS OF THE 12TH WEB FOR ALL Conference (W4A '15). ACM, New York, NY, USA, Article 35, p. 01-13, 2015. Disponível em: http://dx.doi.org/10.1145/2745555.2746653 . Acesso em: 23 mar. 2018.

SALTON, Bruna. Criando documentos digitais acessíveis Word, PowerPoint e PDF. IF Bento Gonçalves. Disponível em:

http://blog.aai.ifrs.edu.br/arquivos/criando documentos digitais acessiveis.pdf . Acesso em: 24 jul. 2017.

SILUK, Ana Cláudia Pavão; PAVÃO, Sílvia Maria de Oliveira. Educação Especial: práticas pedagógicas a distância na formação de professores para o Atendimento Educacional Especializado (AEE). ETD - Educação Temática Digital. Campinas, SP, v.14 n.2 p.61-74, jul./dez. 2012. ISSN 1676-2592. Disponível em:

https://periodicos.sbu.unicamp.br/ojs/index.php/etd/article/view/1222. Acesso em: 20 ago. 2017.

SILVA, Cláudia; SACRAMENTO, Carolina. Orientações para criação de documentos acessíveis no Microsoft Word. UNIRIO. Núcleo de Acessibilidade e Usabilidade (NAU). Disponível em: http://nau.uniriotec.br/images/pdf/guia/v2-guiaWord.pdf . Acesso em: 29 jul. 2017.

SIMÃO, Joaquim, NOMURA, Shigueo. Análise experimental de ferramentas case para documentação. Disponível em:

http://www.ceel.eletrica.ufu.br/artigos2014/ceel2014 artigo035 r01.pdf . Acesso em: 05 ago. 2017.

SONZA, Andréa Poletto; SALTON, Bruna Poletto; STRAPAZZON, Jair Adriano (Org.). O uso pedagógico dos recursos de tecnologia assistiva. Porto Alegre: Companhia Rio-grandense de Artes Gráficas (CORAG), 2015. 224 p. Disponível em:

http://cta.ifrs.edu.br/publicacoes/visualizar/81 . Acesso em: 09 jul. 2017.

* Revisão gramatical do texto sob responsabilidade de:

Marileia Marchezan

E-mail: marileiamarchezan@gmail.com 